\title{
Optimasi Kombinasi Carbomer dan CMC-Na dalam Sediaan Gel Pewarna Rambut Ekstrak Bunga Telang (Clitoria ternatea L.)
}

\section{The Optimization of the Combination of Carbomer and CMC-Na in the Hair Dye Gel Containing Butterfly Pea (Clitoria ternatea L.) Flower Extracts}

\author{
Lia Mardiana $^{1 *}$, Titik Sunarni ${ }^{1}$, Mimiek Murukmihadi ${ }^{2}$ \\ ${ }^{1}$ Program Pasca Sarjana Farmasi, Universitas Setia Budi, Jl. Letjen Sutoyo, Mojosongo, \\ Jebres, Surakarta 57127, Indonesia \\ ${ }^{2}$ Fakultas Farmasi, Universitas Gadjah Mada, Jl. Sekip Utara, \\ Sleman, Yogyakarta 55281, Indonesia \\ *Corresponding author email: lia.mrdiana17@gmail.com
}

Received 29-12-2019 Accepted 11-06-2020 Available online 01-07-2020

\begin{abstract}
ABSTRAK
Ekstrak bunga telang (Clitoria ternatea L.) dapat digunakan sebagai pewarna alami karena mengandung pigmen antosianin. Penelitian ini bertujuan untuk mengetahui pengaruh dari kombinasi carbomer dan CMC-Na terhadap stabilitas sifat fisik dan pewarnaan gel serta iritasi formula optimum yang diperoleh. Serbuk kering bunga telang dimaserasi menggunakan gelombang ultrasonik dengan air yang diasamkan dengan asam tartrat sebagai pelarut. Ekstrak yang diperoleh dari penyaringan vakum kemudian dikeringkan dengan metode freeze dry selama 3 hari. Formula optimum yang diperoleh diuji iritasi, stabilitas mutu fisik dengan metode freeze and thaw selama 3 siklus, dan stabilitas warnanya terhadap lama pewarnaan pada rambut, pencucian serta pengaruh sinar matahari. Hasil menunjukkan bahwa carbomer dominan meningkatkan viskositas, daya lekat, dan pH gel sedangkan CMC-Na dominan meningkatkan daya sebar gel. Interaksi dari carbomer dan CMC-Na meningkatkan viskositas, daya lekat, $\mathrm{pH}$, dan daya sebar. Formula optimum diperoleh dari kombinasi carbomer dan CMC-Na masing-masing pada konsentrasi 1,66 dan $6,00 \%$. Tidak terdapat perbedaan respon antara prediksi dengan perlakuan. Viskositas, daya lekat, daya sebar, dan $\mathrm{pH}$ gel tidak stabil $(p<0,05)$ selama 3 siklus.
\end{abstract}

Kata kunci: bunga telang, carbomer, CMC-Na, factorial design, pewarna rambut.

\section{ABSTRACT}

Anthocyanins in butterfly pea (Clitoria ternatea L.) flower extracts have a potential use as a natural dye. A gel is a convenient preparation for hair dye. This research aimed to evaluate the effects of the combination of carbomer and CMC-Na on the physical 
attributes of the hair dye gel, find out the optimal formula composition, as well as evaluate the coloration, physical stability, and irritation of the optimized formula. The powdered butterfly pea flower was macerated in tartaric acid-acidified water using the ultrasonic wave. The obtained filtrates were dried by the freeze-drying process for 3 days. The irritation, physical stability (by freeze and thaw method in 3 cycles), and coloration stability tests were conducted to determine the optimized formula of the gel. The result showed that carbomer had the dominant effects in improving viscosity, adhesiveness, and $\mathrm{pH}$ of the gel; while CMC-Na showed a dominant effect in increasing the gel dispersion. The optimal formula for butterfly pea flower hair dye contained carbomer and CMC-Na in a concentration of 1.66 and $6.00 \%$, respectively. There was no significant difference between the response in experiment and prediction. Viscosity, adhesiveness, dispersion were found to be unstable $(p<0.05)$ after three cycles.

Key words: butterfly pea flower, carbomer, CMC-Na, factorial design, hair dye.

\section{Pendahuluan}

Rambut merupakan aset bagi wanita agar bisa tampil cantik dan menawan. Oleh karena itu, wanita akan melakukan banyak cara agar rambut mereka tetap terlihat indah dan sehat. Salah satu cara untuk menutupi warna rambut karena telah kehilangan pigmen warna aslinya adalah dengan penambahan warna (Hair Tinting). Faktor zat warna dan pewangi sangat penting dalam sediaan kosmetik pewarna rambut. Sediaan pewarna rambut yang sekarang ini beredar dimasyarakat sebagian besar menggunakan bahan pewarna sintetik. Salah satu tanaman yang mempunyai khasiat sebagai pewarna rambut adalah bunga telang (Clitoria ternatea $\mathrm{L}$ ).

Tanaman bunga telang memiliki Pigmen alami warna biru antosianin jenis Delphinidin Glikosida yang berpotensi dan mempengaruhi karakteristik bunga telang (Tantituvanont et al., 2008). Antosianin berperan dalam menghasilkan warna merah, biru hingga ungu pada beberapa jenis bunga, buah, dan daun. Kandungan antosianin dalam bunga telang mencapai 40,58 mg/L (Kusrini et al, 2017). Tingginya kadar antosianin dari bunga telang dapat digunakan sebagai bahan untuk membuat pewarna rambut alami.

Gel adalah salah satu bentuk sediaan farmasi yang bersifat dispersi semisolid dengan jumlah bahan penyusun formula yang relatif sedikit dan viskositas yang cenderung konstan menjadikan gel sebagai salah satu pilihan di masyarakat yang paling digemari dalam pembuatan sediaan pewarna rambut (Ansel, 2008). Bahan utama pembentuk gel adalah gelling agent, CMC-Na merupakan basis gel golongan polimer semi sintetik dan carbomer termasuk basis golongan sintetik. Penggunaan CMC-Na dapat membuat gel menjadi tidak jernih karena menghasilkan dispersi koloid dalam air dengan munculnya bintikbintik dalam gel. Gel berbasis CMC-Na memiliki diameter penyebaran yang 
lebih kecil dibanding gel berbasis carbomer. Salah satu metode yang digunakan untuk mendapatkan kombinasi Carbomer dan CMC-Na yang menghasilkan formula dengan sifat fisik optimal adalah Factorial design, kelebihan metode ini yaitu dengan jumlah percobaan sedikit dapat menentukan persamaan dan contour plot sehingga didapatkan kombinasi faktor yang diinginkan. Penelitian ini bertujuan untuk mengetahui secara ilmiah pengaruh gelling agent dalam sediaan gel serta mengetahui formula optimum gel pewarna rambut ekstrak bunga telang berdasarkan daya lekat, daya sebar, $\mathrm{pH}$, dan viskositas dengan menggunakan metode Factorial design.

\section{Metode Penelitian}

Alat dan Bahan

Alat-alat yang digunakan adalah neraca analitik (Ohaus), Spektrofotometer UV-Vis (Shimadzu), pH-meter, alat-alat gelas (Pyrex), waterbath, botol timbang, oven, seperangkat alat uji daya lekat, seperangkat alat uji daya sebar, viskometer Rion VT-04, vakum rotary evaporator. Bahan-bahan yang digunakan adalah bunga telang yang diperoleh dari Karanganyar, Jawa Tengah. Bahan kimia yang digunakan jika tidak dinyatakan lain berkualitas farmasetik (pharmaceutical grade) yaitu etanol, asam tartarat, CMC-Na, carbomer, $\mathrm{NaOH}$, nipagin, nipasol, air suling, gliserin, ekstrak bunga telang, dan rambut putih.

Jalannya Penelitian
1. Persiapan sampel

Sampel yang digunakan dalam penelitian adalah bunga telang (Clitoria ternatea L.) dengan umur kurang dari satu tahun yang berwarna biru dan dipanen pada pagi hari.

2. Pembuatan ekstrak

Ekstrak bunga telang dimaserasi dengan pelarut air yang diasamkan dengan asam tartarat menggunakan gelombang ultrasonik hingga didapatkan filtrat hasil penyaringan dengan vacuum fitrat. Selanjutnya filtrat dikeringkan dengan metode pengeringan freeze dry selama3 hari.

3. Formulasi gel pewarna rambut

Rancangan formula pewarna rambut (Tabel 1) dibuat berdasarkan acuan Sutriningsih et al. (2017), 4 formula gel dilakukan replikasi 2 kali sehingga terdapat 8 formula. Replikasi bertujuan untuk melihat titik kritis pada desain sehingga akan didapatkan persamaan untuk mencari formula optimum. Pembuatan pewarna rambut dimulai dengan penimbangan bahan-bahan yang diperlukan. Bahan-bahan ditimbang sesuai dengan berat pada formula, selanjutnya dibuat basis gel dengan urutan: CMC-Na dikembangkan dalam air panas 20 kalinya pada beaker glass. Carbomer dilarutkan dalam air panas dan ditambahkan trietanolamin, dicampur CMC-Na yang telah dikembangkan sebelumnya, ditambahkan nipagin yang telah dilarutkan dalam gliserin, diaduk hingga diperoleh massa gel yang transparan, ditambahkan 
ekstrak bunga telang dan sisa air suling ke dalam campuran hingga didapatkan sediaan gel yang homogen. Delapan formula gel yang diperoleh, diuji organoleptis, homogenitas, $\mathrm{pH}$, daya lekat, daya sebar, dan viskositas. Data-data tersebut dimasukkan ke dalam Design expert Software untuk mendapatkan formula optimum. Setelah mendapatkan formula optimum, maka dibuatlah gel dan diuji kualitasnya meliputi mutu fisik gel antara lain, organoleptis, homogenitas, $\mathrm{pH}$, daya lekat, daya sebar, dan viskositas.

\section{Hasil dan Pembahasan}

Formula optimum gel pewarna rambut didapatkan desirability 0,774 yang diprediksi dari daerah optimum tersebut dengan komposisi carbomer 1,66\% dan CMC-Na 6\%. Program juga memprediksi rancangan formula untuk respon viskositas sebesar 93,04 dPas, daya sebar sebesar $4,00 \mathrm{~cm}$, daya lekat sebesar 41,72 detik, dan $\mathrm{pH}$ sebesar 6,32 .

Pada pengamatan organoleptis, gel formula optimum pewarna rambut memiliki warna ungu gelap dari siklus pertama pembuatan hingga pada siklus ketiga. Warna yang stabil dikarenakan ekstrak bunga telang mengandung asam tartarat dimana zat antosianin akan stabil pada suasana asam sehingga warna yang dihasilkan mampu bertahan hingga siklus ketiga penyimpanan.

Persamaan daya sebar dari factorial design menggunakan program Design expert sebagai berikut:

$Y=+7,40-1,49(A)+0,036(B)+0,053(A)(B)$

Berdasarkan nilai koefisien persamaan pada Persamaan 1, dapat dilihat pengaruh masing-masing komponen dan interaksi dari dua komponen tersebut. Komponen carbomer sebesar -1,4) dan CMC-Na 0,036. Carbomer merupakan faktor dominan yang menyebabkan penurunan daya sebar gel.

Tabel 1. Fomula gel pewarna rambut

\begin{tabular}{lcccc}
\hline & Bahan & \multicolumn{3}{c}{ Formula (\%) } \\
& F1 & F2 & F3 & F4 \\
\hline Ekstrak bunga telang & 2 & 2 & 2 & 2 \\
Carbomer & $\mathbf{0 , 5}$ & $\mathbf{2}$ & $\mathbf{0 , 5}$ & $\mathbf{2}$ \\
CMC-Na & $\mathbf{3}$ & $\mathbf{6}$ & $\mathbf{6}$ & $\mathbf{3}$ \\
Trietanolamin & 2 & 2 & 2 & 2 \\
Gliserin & 3 & 3 & 3 & 3 \\
Metil Paraben & 0,2 & 0,2 & 0,2 & 0,2 \\
Air Suling ad & 100 & 100 & 100 & 100 \\
\hline
\end{tabular}


Uji stabilitas daya sebar dapat dilihat pada Gambar 1. Sediaan gel pewarna rambut mengalami peningkatan daya sebar dari siklus pertama hingga siklus ketiga penyimpanan. Daya sebar gel pada formula optimum antara $3,6-4,3 \mathrm{~cm}$ yang menunjukkan bahwa sediaan tidak memenuhi persyaratan. Hal ini disebabkan gelling agent CMC-Na dimasukkan ke dalam air, $\mathrm{Na}^{+}$lepas dan terganti dengan ion $\mathrm{H}^{+}$dan membentuk $\mathrm{CMCH}$ yang akan meningkatkan viskositas (Bochek et al., 2002), sehingga gel yang berbasis CMC-Na memiliki diameter penyebaran yang lebih kecil.

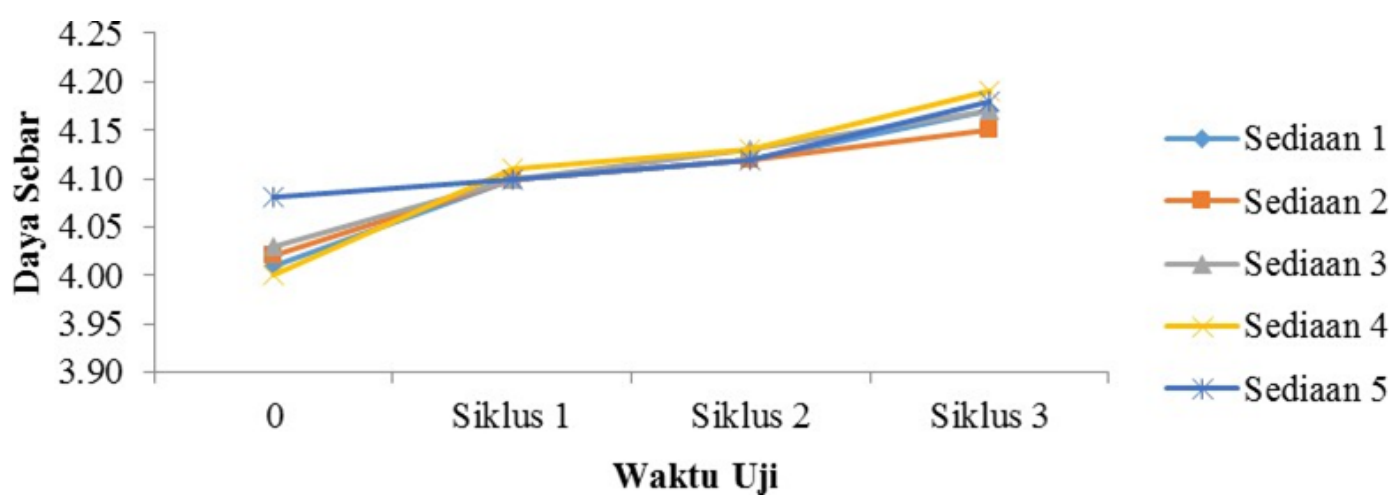

Gambar 1. Hasil uji daya sebar gel formula optimum pewarna rambut.

Persamaan daya lekat dari Factorial design menggunakan program Design expert dapat dilihat pada Persamaan 2.

$Y=+17,97+13,80(A)+11,83(B)+12,19(A)(B)$

Berdasarkan nilai koefisien Persamaan 2, dapat dilihat pengaruh masing-masing komponen dan interaksi dari dua komponen tersebut. Komponen carbomer $(13,80)$ dan CMC-Na $(11,83)$, carbomer merupakan faktor dominan yang peningkatan daya lekat gel.

Uji stabilitas daya lekat pada Gambar 2, selama tiga siklus penyimpanan adalah antara 41-41,9 detik. Sediaan gel mengalami penurunan selama waktu pemeriksaan. Kemampuan gel melekat pada rambut dapat mempengaruhi efek pewarnaan yang dihasilkan. Semakin lama sediaan melekat pada rambut, maka warna yang diberikan oleh sediaan akan lebih optimal sebab sediaan akan lebih lama kontak dengan permukaan.

Persamaan viskositas dari Factorial Design ditunjukkan pada Persamaan 3.

$Y=+56,94+31,96(A)+4,21(B)+11,63(A)(B)$

Berdasarkan nilai koefisien pada Persamaan 3, dapat dilihat pengaruh 
masing-masing komponen dan interaksi dari dua komponen tersebut. Komponen carbomer $(31,96)$ dan CMC-Na $(4,21)$, yang paling dominan dalam meningkatkan viskositas gel adalah carbomer.

Uji stabilitas viskositas ditunjukkan pada Gambar 3. Sediaan mengalami penurunan dari siklus pertama pengujian hingga siklus ketiga, hal ini dapat disebabkan karena keluarnya cairan yang terjerat dalam gel akibat adanya kontraksi matriks dalam gel. Penurunan viskositas tersebut kemungkinan dapat disebabkan karena adanya pengaruh polimer terhadap perubahan suhu dimana ketika suatu gel disimpan pada suhu panas akan membentuk bola (disentangle) mengakibatkan viskositas gel semakin menurun. Berkurangnya kekentalan gel dapat disebabkan oleh faktor luar seperti suhu ruang selama waktu penyimpanan. Faktor lain yang dapat mempengaruhi terjadinya pergeseran nilai viskositas yaitu adanya pertumbuhan bakteri pada sediaan gel yang dapat membuat suasana asam pada sediaan gel.

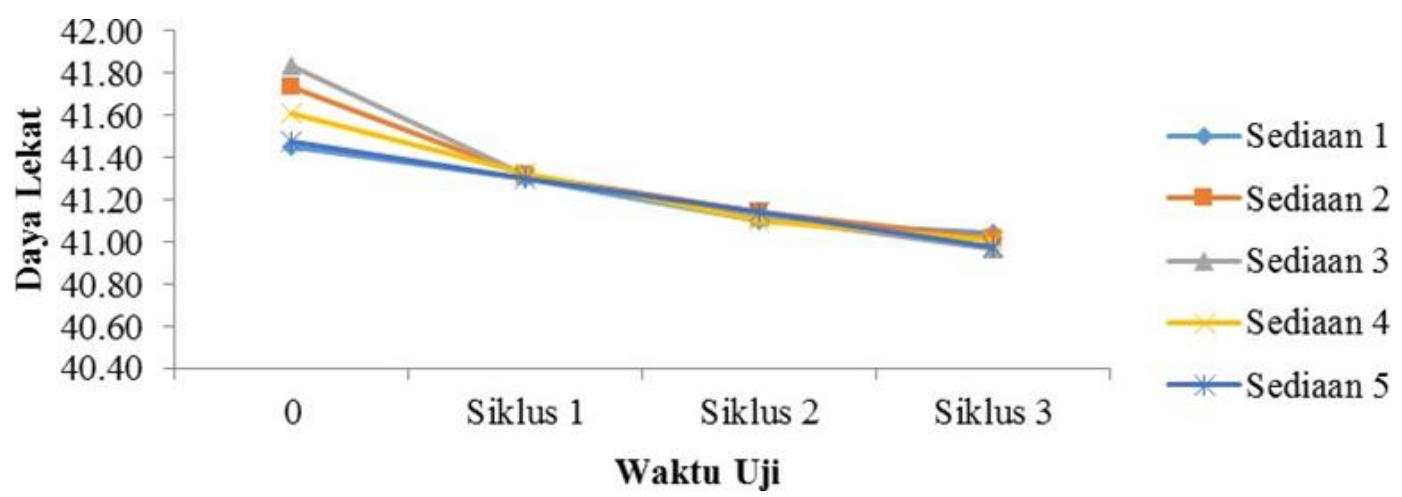

Gambar 2. Hasil uji daya lekat gel formula optimum pewarna rambut.

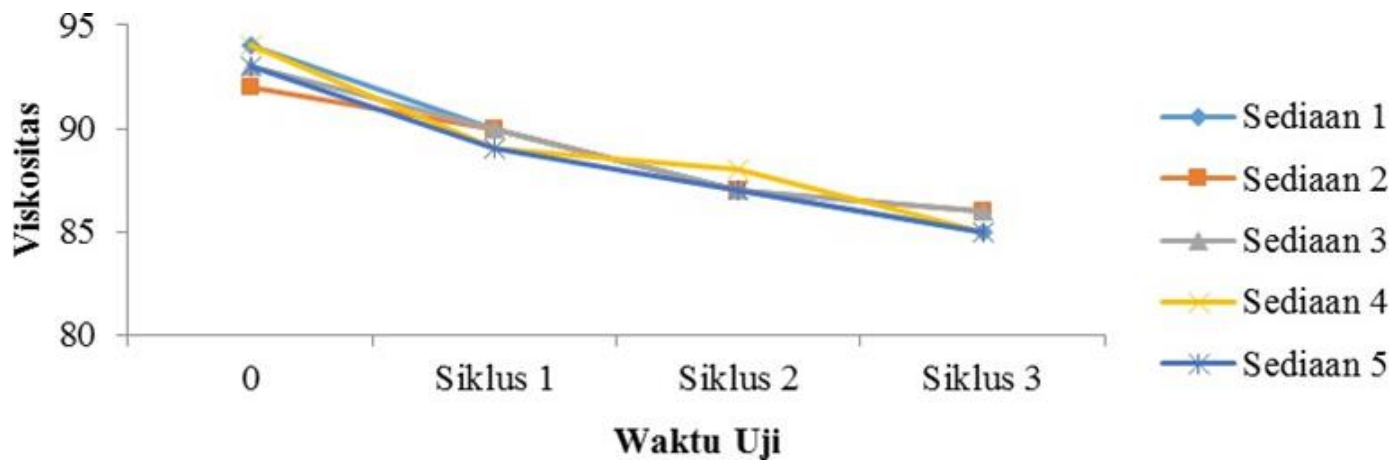

Gambar 3. Hasil uji viskositas formula optimum pewarna rambut. 
Persamaan $\mathrm{pH}$ dari persamaan Factorial Design menggunakan program Design Expert dapat dilihat pada Persamaan 4.

$Y=+3,91-0,21(A)-0,015(B)-0,047(A)(B)$

Dari Persamaan 4 menunjukkan bahwa interaksi antara kedua faktor menurunkan respon sebesar -0,021. Carbomer menurunkan respon $\mathrm{pH}$ sebesar-0,21 dan CMC-Na menurunkan respon sebesar $-0,015$. Hasil Persamaan 4 menunjukkan bahwa faktor carbomer paling berpengaruh terhadap respon $\mathrm{pH}$ gel, karena carbomer bersifat asam dan mempunyai $\mathrm{pH}$ 2,5-4,0 (Rowe et al., 2009).

Pada pengamatan stabilitas $\mathrm{pH}$ yang dilakukan setiap siklus selama 3 siklus, menghasilkan gel yang memiliki $\mathrm{pH}$ antara 5,8-6,3 yang mengalami perubahan selama penyimpanan (Gambar 4). Sediaan yang dihasilkan bersifat agak asam, $\mathrm{pH}$ yang bersifat terlalu asam dapat menyebabkan iritasi sedangkan $\mathrm{pH}$ yang terlalu basa menyebabkan kulit bersisik.

Pengujian t-test dilakukan untuk menguji perbedaan nilai daya sebar, daya lekat, viskositas, dan $\mathrm{pH}$ antara kelompok respon prediksi dan percobaan. Hasil menunjukkan bahwa tidak terdapat perbedaan yang signifikan antara kelompok prediksi dan percobaan pada daya sebar gel pewarna rambut. Hal tersebut ditunjukkan pada nilai-nilai probabilitas daya sebar sebesar 0,115 > 0,05 , daya lekat $0,268>0,05$, viskositas

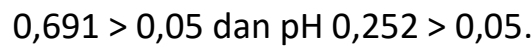

Pewarnaan dilakukan pada rambut uban yang telah dikeringkan dan dicuci pada menit ke-30, 60, 90, dan 120 . Hasil pengamatan secara visual menunjukkan perubahan warna pada menit ke-30 menit yang berwarna kuning kehijauan, menit ke-60 berwarna hijau muda, menit ke-90 berwarna hijau (Gambar 5). Hasil pengamatan secara visual menunjukkan perubahan warna paling jelas yang mengarah pada menit ke-120 yang berwarna hijau tua.

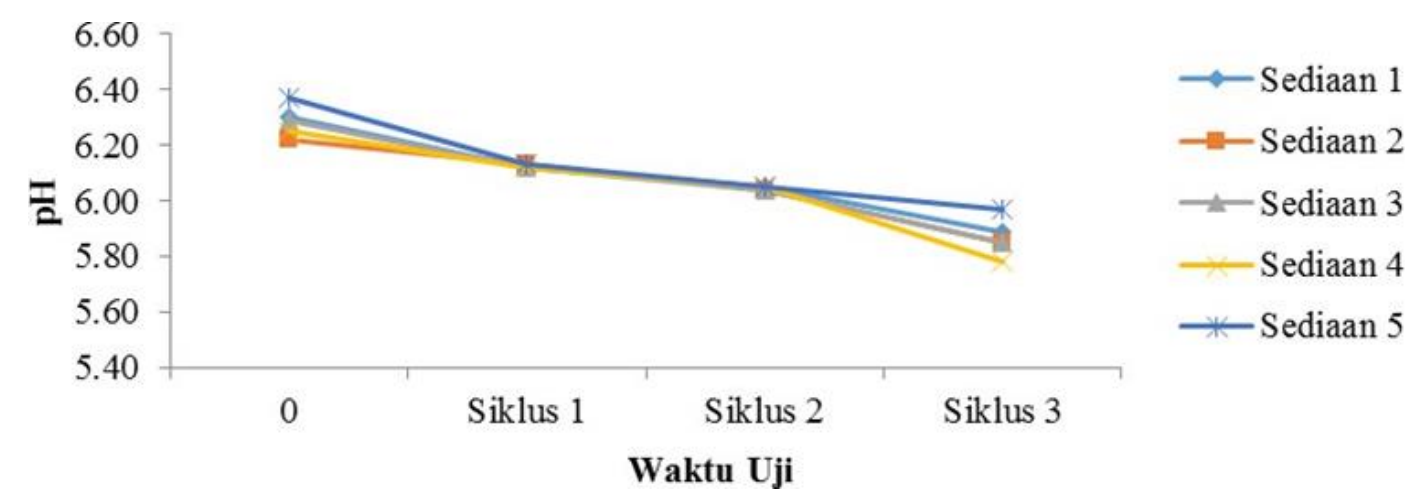

Gambar 4. Hasil uji pH formula optimum pewarna rambut. 


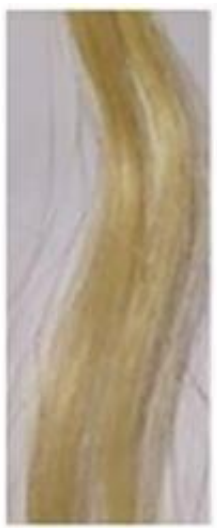

A

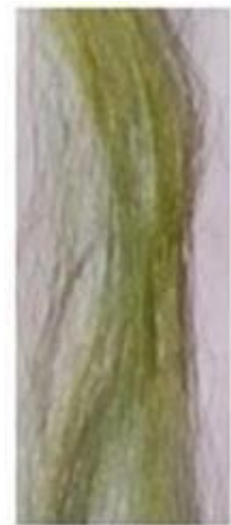

B

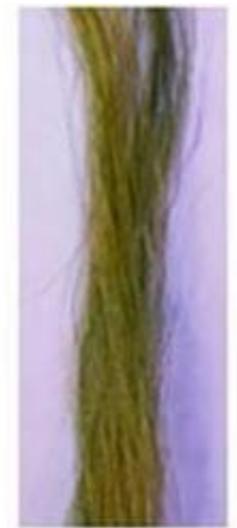

$\mathrm{C}$

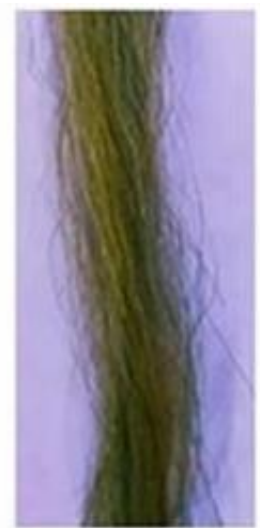

$\mathrm{D}$

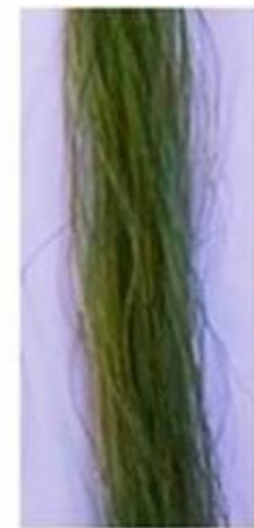

$\mathrm{E}$

Gambar 5. Uji stabilitas terhadap lama pewarnaan, (A) sebelum pewarnaan, (B) setelah 30 menit, (C) setelah 60 menit, (D) setelah 90 menit, dan (E) setelah 120 menit.

Pada uji stabilitas warna terhadap pencucian diperoleh hasil bahwa warna pudar terjadi setelah pencucian ke-3 pada pewarnaan rambut 30 dan 60 menit. Sedangkan pada pewarnaan 90 dan 120 menit warna pudar pada pencucian ke-4. Lama waktu pewarnaan berpengaruh terhadap warna yang dihasilkan karena daya lekat yang lama memungkinkan zat warna pada sediaan dapat menempel lebih kuat. Warna yang ditimbulkan oleh formula optimum saat diaplikasikan pada rambut menghasilkan warna hijau yang menunjukkan $\mathrm{pH}$ berubah menjadi basa. $\mathrm{pH}$ sediaan berkisar 5,8-6,7 sedangkan $\mathrm{pH}$ normal rambut berkisar 3,6-5 (Dias et al., 2014). Hal ini dapat disebabkan oleh kadar $\mathrm{pH}$ dalam rambut berbeda tergantung dengan jenis rambut seperti rambut yang pernah diproses dengan bahan kimia, rambut yang berminyak, dan rambut yang kering menyebabkan $\mathrm{pH}$ rambut menjadi tidak seimbang dan warna yang dihasilkan pada rambut tidak sesuai dengan warna sediaan gel.

Setelah terpapar sinar matahari langsung, warna rambut mulai pudar. Hal ini dikarenakan zat warna tidak menembus kutikula dan masuk ke dalam korteks rambut sehingga warna rambut mudah berubah. Sinar matahari dapat mempengaruhi terjadinya perubahan warna pada hasil. Pada aplikasi pewarna rambut terhadap matahari diperoleh bahwa sediaan gel pewarna rambut yang dihasilkan tidak stabil terhadap paparan sinar matahari (Gambar 6).

Uji iritasi sediaan pewarna rambut pada kulit kelinci normal menunjukkan terjadi eritema yang disebabkan oleh zat aktif yang mengandung polifenol yang bersifat asam (Oktaf, 2013). Pada kontrol negatif (Basis gel tanpa zat aktif) terjadi eritema, 
hal ini disebabkan zat tambahan gel berupa Trietanolamin yang dapat menyebabkan iritasi ringan (Bochek et al., 2002). Hasil uji iritasi primer pada kelinci dapat disimpulkan ternyata zat uji yang digunakan yaitu kontrol negatif
(Basis gel tanpa zat aktif) terjadi eritema, hal ini disebabkan zat tambahan gel berupa trietanolamin yang dapat menyebabkan iritasi ringan (Bochek et al., 2002).
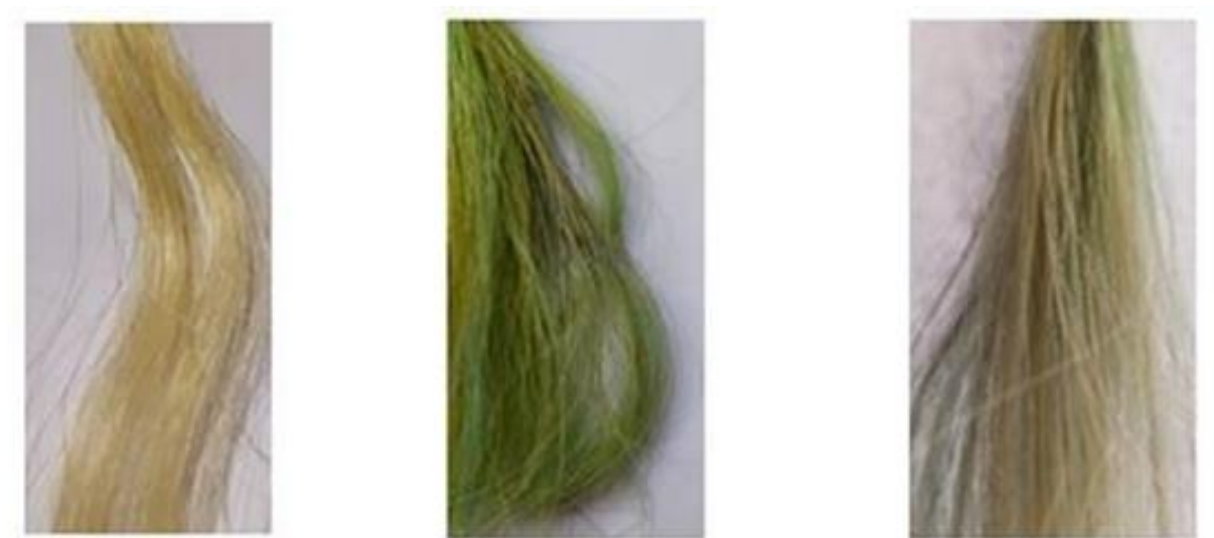

\section{Rambut tanpa warna Setelah diwarnai Setelah terpapar matahari}

Gambar 6. Uji stabilitas terhadap lama pewarnaan.

Hasil uji iritasi primer pada kelinci dapat disimpulkan ternyata zat uji yang digunakan yaitu sediaan gel pewarna rambut dapat mengakibatkan iritasi ringan pada kulit. Penyebab terjadinya iritasi pada kelinci adalah karena ekstrak yang bersifat asam yang tidak balance dengan standar $\mathrm{pH}$ kulit antara 4,5-6,5 dan sediaan uji memiliki $\mathrm{pH}$ dengan kisaran 5,8-6,7 yang agak asam. Pada uji hedonik terhadap 20 orang masyarakat umum dan berada di rentang usia 20-50 tahun disimpulkan bahwa tekstur gel lembut, warna gel cukup disukai, aroma dapat diterima, mudah diambil dan dikeluarkan dari wadah. Namun ada 3 orang tidak suka dengan warna gel, dan 4 orang tidak suka dengan aroma lavender dari gel pewarna rambut.

Uji hedonik dilakukan terhadap 20 orang masyarakat umum dan berada di rentang usia 20-50 tahun. Pengujian hedonik atau uji kesukaan dilakukan untuk mengetahui seberapa besar responden menyukai sediaan yang dibuat. Hal ini berkaitan dengan penerimaan masyarakat terhadap sediaan gel pewarna rambut yang dibuat. Kesimpulan dari uji hedonik ini yaitu tekstur gel lembut, warna gel cukup disukai, aroma dapat diterima, mudah diambil dan dikeluarkan dari wadah. Namun ada 3 orang tidak suka dengan warna gel, dan 4 orang tidak 
suka dengan aroma lavender dari gel pewarna rambut.

\section{Simpulan}

Kombinasi optimum antara carbomer dan CMC-Na sebagai basis pada pembuatan gel pewarna rambut bunga telang (Clitoria ternatea L.) menunjukkan bahwa carbomer dominan meningkatkan viskositas, daya lekat, dan $\mathrm{pH}$ gel, sedangkan CMC-Na dominan meningkatkan daya sebar gel. Interaksi dari carbomer dan CMC-Na meningkatkan viskositas, daya lekat, $\mathrm{pH}$, dan daya sebar sediaan. Kombinasi antara carbomer dan CMC-Na sebagai basis pada pembuatan gel pewarna rambut bunga telang dengan metode Factorial Design yaitu carbomer 1,66\% dan CMC-Na 6,00\%. Formula optimum gel pewarna rambut bunga telang tidak stabil dalam penyimpanan selama tiga siklus setelah pembuatan. Formula optimum gel pewarna rambut bunga telang menyebabkan iritasi pada kulit kelinci ditandai dengan eritema ringan. Formula optimum gel pewarna rambut bunga telang berdasarkan uji hedonik (tekstur, warna, aroma, dan kemudahan) merupakan gel yang disukai oleh panelis. Formula optimum gel pewarna rambut memberikan warna hijau pada rambut putih namun pada rambut hitam tidak memberikan warna.

\section{Daftar Pustaka}

Ansel, H.C. 2008. Pengantar Bentuk Sediaan Farmasi. Diterjemahkan oleh Ibrahim, F. Edisi 4. Jakarta: Universitas Indonesia Press.
Bochek, A.M., Yusupova, L.D., Zabivalova, N.M., Petropavlovskii, G.A. 2002. Rheological properties of aqueous $\mathrm{H}$ carboxymethyl cellulose solutions with various additives. Russian Journal of Applied Chemistry, 75:4-7.

Dias, M., Almeida, A., Cecato, P. 2014. The shampoo ph can affect the hair: myth or reality. International Journal of Trichology, 6(3):95-99.

Kusrini, E., Tristantini, D., Izza, N. 2017. Uji aktivitas ekstrak bunga telang (Clitoria ternatea L.) sebagai agen anti katarak. Jurnal jamu Indonesia, 2:30-36.

Oktaf, R. 2013. Identifikasi senyawa aktif dalam ekstrak etanol kayu secang (Caesalpinia sappan L.). Prosiding Semirata, 215-218. 1012 Mei 2013, Lampung Indonesia.

Rowe, R.C., Sheskey, P.J., Quinn, M.E. 2009. Handbook of Pharmaceutical Excipients. New York: Pharmaceutical Press.

Sutriningsih, Sagala, Z., Meliana. 2017. Uji efektivitas dan uji iritasi gel pewarna rambut dari ekstrak biji buah pepaya (Carica papaya L). Jurnal Muara, 1(1):59-63.

Tantituvanont, A., Werawatganone, P., Jiamchaisri, P., Manopakdee, K. 2008. Preparation and stability of butterfly pea color extract loaded in microparticles prepared by spray drying. Thai Journal of Pharmaceutical Sciences. 